\title{
Analgesic and anti-inflammatory effects of ethanol extracted leaves of selected medicinal plants in animal model
}

\author{
Mohammad M. Hassan ${ }^{1}$, Shahneaz A. Khan ${ }^{1}$, Amir H. Shaikat ${ }^{1}$, Md. Emran Hossain ${ }^{2}$, Md. Ahasanul Hoque ${ }^{1}$,
} Md Hasmat Ullah ${ }^{3}$, Saiful Islam ${ }^{4}$

1. Department of Physiology, Biochemistry and Pharmacology; Faculty of Veterinary Medicine, Chittagong Veterinary and Animal Sciences University, Khulshi, Chittagong-4202, Bangladesh;2. Department of Animal Scienc and Nutrition, Faculty of Veterinary Medicine, Chittagong Veterinary and Animal Sciences University, Khulshi, Chittagong-4202, Bangladesh;

3. Department of Biochemistry and Molecular Biology, Jahangirnagar University, Savar, Dhaka, Bangladesh; 4. Bangladesh Council of Scientific and Industrial Research (BCSIR), Chittagong, Bangladesh

Corresponding author: Mohammad Mahmudul Hassan, Email: miladhasan@yahoo.com; Cell: +88-01554326951 Received: 17-06-2012, Accepted: 08-07-2012, Published online: 03-12-2012

How to cite this article: Hassan MM, Khan SA, Shaikat AH, Hossain ME, Hoque MA, Ullah MH and Islam S. (2013) Analgesic and anti-inflammatory effects of ethanol extracted leaves of selected medicinal plants in animal model, Vet World 6(2): 6871. doi: 10.5455/vetworld.2013.68-71

\begin{abstract}
Aim: The research was carried out to investigate the analgesic and anti-inflammatory effects of ethanol extract of Desmodium pauciflorum, Mangifera indica and Andrographis paniculata leaves.

Materials and Methods: In order to assess the analgesic and anti-inflammatory effects acetic acid induced writhing response model and carrageenan induced paw edema model were used in Swiss albino mice and Wistar albino rats, respectively. In both cases, leaves extract were administered $(2 \mathrm{gm} / \mathrm{kg}$ body weight) and the obtained effects were compared with commercially available analgesic and anti-inflammatory drug Dclofenac sodium (40mg/kg body weight). Distilled water ( $2 \mathrm{ml} / \mathrm{kg}$ body weight) was used as a control for the study.
\end{abstract}

Results: In analgesic bioassay, oral administration of the ethanol extract of leaves were significantly $(p<0.01)$ reduced the writhing response. The efficacy of leaves extract were almost 35\% in Desmodium pauciflorum, 56\% in Mangifera indica and $34 \%$ in Andrographis paniculata which is found comparable to the effect of standard analgesic drug diclofenac sodium (76\%). Leaves extract reduced paw edema in variable percentages but they did not show any significant difference among the leaves.

Conclusion: We recommend further research on these plant leaves for possible isolation and characterization of the various active chemical substances which has the toxic and medicinal values.

Key words: acetic acid, analgesic, anti-inflammatory, carrageenan, diclofenac sodium, medicinal plant

\section{I ntroduction}

Medicinal plants are of great importance to the health of individuals and communities. The medicinal value of these plants lies in some chemical active substances that produce a definite physiological action on the human body. The most important of these chemically active constituents of plants are alkaloid, tannin, flavonoid and phenolic compounds. Many of the indigenous medicinal plants are used for medicinal purposes [1]. In the last few years, a number of studies have been conducted in different medicinal plants in different countries to prove the medicinal efficiency [25]. Plants are rich in a wide variety of secondary metabolites, such as tannins, terpenoids, alkaloids, and flavonoids, which have been found in vitro to have medicinal properties. The advent of science into the search for antibiotics largely depends on some of these medicinal plants as raw materials. For many years, medicine had depended exclusively on leaves, flowers and barks of plants; only recently have synthetic drugs come into use. At present nearly $30 \%$ or more of the modern pharmacological drugs are derived directly or indirectly from plants and in homeopathic or ayurvedic medicines, medicinal plants, their parts and extracts dominate the scenes.

Desmodium pauciflorum is a small shrub of tropical region which has been used in traditional system in Indian sub-continent medicine as antiemetic and antiinflammatory drugs. Mangifera indica grows in the tropical and subtropical region and its parts are commonly used in folk medicine for a wide variety of remedies [6,7]. Andrographis paniculata commonly known as Kalmegh in Bangladesh is widely used in traditional system in Indian medicine. The pharmacological properties of the Kalmegh showed varying degrees of analgesic, anti-pyretic and anti-inflammatory activities $[8,9]$. Drugs which are used presently for the management of pain and inflammatory conditions are either steroidal (corticosteroids) or non steroidal (aspirin). All of these drugs possess toxic effects at variable level like renal failure, allergic reactions, and occasionally hearing loss, and they can increase the risk of hemorrhage by affecting platelet function [10]. The risk of death as a result of use of NSAIDs is 1 in 10,000 for young adults aged 16-45 and the risk increases tenfold for those over 75 years old [11]. Moreover synthetic drugs are very expensive to develop [11]. On the contrary many medicines of plant origin had been used since long time without any adverse effects. It is therefore essential that efforts should be taken to develop new drugs of plant origin that possess antinociceptive and anti-inflammatory effects which will 
Table-1. Effect of ethanol leaves extract on acetic acid induced writhing response

\begin{tabular}{lccc}
\hline Treatment & Dose/Kg body weight & (Mean \pm SEM) & Analgesic activity (\%) \\
\hline Distilled water & $2 \mathrm{ml}$ & $66.7 \pm 2.2$ & - \\
Diclofenac sodium & $40 \mathrm{mg}$ & $16.5 \pm 1.7^{* *}$ & $76 \%$ \\
D. pauciflorum & $2 \mathrm{gm}$ & $43.5 \pm 1.3^{\star *}$ & $35 \%$ \\
M. indica & $2 \mathrm{gm}$ & $29.5 \pm 2.7^{\star *}$ & $56 \%$ \\
A. paniculata & $2 \mathrm{gm}$ & $44.2 \pm 1.9^{* *}$ & $34 \%$ \\
\hline
\end{tabular}

**Highly significant compared to control $(\mathrm{P}<0.01)$

be economically feasible, as well as contains lesser side effects.

In Bangladesh, very few works have been done to explore the possibilities of utilizing the locally available herbs and shrubs in veterinary practice. Keeping these views in mind, the present work was designed to investigate the analgesic and anti-inflammatory activities of selective available plants in Bangladesh.

\section{Materials and Methods}

Sample collection and leaves extract preparation: The leaves of Desmodium pauciflorum, Mangifera indica and Andrographis paniculata were collected from Chittagong, Bangladesh. The fresh leaves obtained were washed with fresh water immediately after collection. Leaves were then chopped into small pieces, air-dried at room temperature for 10 days. Dried leaves were ground into powder and stored in an airtight container. After that $750 \mathrm{gm}$ powder from each leaves were taken and suspended in $5 \mathrm{~L}$ ethanol for 7 days at room temperature. Ethanol extract was sieved using cotton plug followed by a Whatman no.1 filter paper. The extract was concentrated under reduced pressure below $50^{\circ} \mathrm{C}$ through rotatory vaccum evaporator. The concentrated extracts were collected in a Petri dish and allowed to air-dry for complete methanol evaporation. Finally, 50gm greenish colored, concentrated leaves extract was obtained from each leaves and kept them in fridge $\left(4^{\circ} \mathrm{C}\right)$.

Experimental animals and diets: Swiss albino mice of both sexes weighing between 25-30g and Wistar Albino rats of the either sex weighing between 150$200 \mathrm{~g}$ obtained from Chittagong, BCSIR laboratories, were used for the experiment. The animals were acclimatized to room temperature $\left(28 \pm 5^{\circ} \mathrm{C}\right)$ with a relative humidity $(55 \pm 5 \%)$ in a standard wire meshed plastic cages under a $12 \mathrm{~h}$ light/12 h dark cycle for 4-5 days prior to the experiment. The animals were supplied with standard pellet diet prepared by BCSIR and adlibitum water. Laboratory experimentation was performed according to the guidelines of Institutional Animal Ethics Committee (IAEC) of BCSIR.

Screening of analgesic activity of leaves extract: Acetic acid induced writhing test model described by Koster et al., [12] was performed to evaluate the analgesic activities of leaves extracts.

Acetic acid induced writhing response model: Fifteen Swiss albino mice were randomly divided into three groups and each group consisting of 5 animals. Control group received only distilled water, positive control group received analgesic drug diclofenac sodium at the dose rate of $40 \mathrm{mg} / \mathrm{kg}$ body weight and treated group received leaves extract at the dose rate of $2 \mathrm{gm} / \mathrm{kg}$ body weight. Ethanol extract leaves, analgesic drug diclofenac sodium and distilled water were administered orally to particular groups, $30 \mathrm{~min}$ prior to acetic acid injection. $1 \%$ acetic acid solution at the dose rate of $3.3 \mathrm{ml} / \mathrm{kg}$ body weight was injected intra-peritoneally in mice and the number of writhing and stretching was counted over 20 minutes period. Finally, \% analgesic activity was calculated by using following formula-

$\%$ Analgesic activity = Mean writhing count (Control groupTreated group) / Mean writhing count of control group x 100

Assay of anti-inflammatory activity of plant extract: Carrageenan induced paw edema model described by Winter et al., [13] was used for evaluating potential anti-inflammatory activities by leaves extract.

Carrageenan induced paw edema model: Fifteen Wistar albino rats were randomly divided into three groups and each group consisting of 5 animals. Control group received only distilled water, positive control group received commercially available analgesic drug diclofenac sodium at the dose rate of $40 \mathrm{mg} / \mathrm{kg}$ body weight and treated group received leaves extract at the dose rate of $2 \mathrm{gm} / \mathrm{kg}$ body weight. Leaves extract, diclofenac sodium and distilled water were administered orally to each group (1hr) one hour prior to the sub-plantar injection of carrageenan. Initially the right hind paw volume of each rat was measured using plethysmometer (UGO Basile, Italy) and then $0.1 \mathrm{ml}$ of $1 \%$ carrageenan was injected subcutaneously into the sub-plantar region of the right hind paw to induce acute inflammation. The volume of right hind paw was measured at $1^{\text {st }}, 2^{\text {nd }}, 3^{\text {rd }}$ and $4^{\text {th }}$ hour after carrageenan injection. The antiinflammatory activity was calculated according to the following formula-

Anti-inflammatory activity $(\%)=(\mathrm{Ct}-\mathrm{Co})$ control - (Ct-Co) treated / (Ct-Co) control $x 100$

Where $\mathrm{Ct}$ is the right hind paw thickness volume (in $\mathrm{mm}^{3}$ ) at time $\mathrm{t}, \mathrm{Co}$ is the right hind paw thickness volume (in $\mathrm{mm}^{3}$ ) before carrageenan injection. $(\mathrm{Ct}-\mathrm{Co})$ control is edema or paw size after carrageenan injection to control rats at time $\mathrm{t}$. $(\mathrm{Ct}-\mathrm{Co})$ treated is edema or paw size after carrageenan injection to treated (reference or sample drug) rats at time $t$.

Statistical analysis: The obtained information was imported, sorted and coded accordingly using Microsoft Excel- 2000. The data was exported from MS Excel-2000 to STATA/IC-11 for analysis. The results were expressed as mean and standard error of mean. Statistical significance between the groups was 
Table-2. Effect of ethanol extract leaves on carrageenan induced paw edema

\begin{tabular}{|c|c|c|c|c|c|c|c|c|c|}
\hline \multirow[t]{2}{*}{ Treatment } & \multirow[t]{2}{*}{ Dose/Kg B W } & \multicolumn{4}{|c|}{ Paw edema Mean \pm SE M (ml) } & \multicolumn{4}{|c|}{ Anti-inflammatory activity (\%) } \\
\hline & & $1^{\text {st }} h r$ & $2^{\text {nd }} h r$ & $3^{\text {rd }} \mathrm{hr}$ & $4^{\text {th }} \mathrm{hr}$ & $1^{\text {st }} \mathrm{hr}$ & $2^{\text {nd }} \mathrm{hr}$ & $3^{\text {rd }} \mathrm{hr}$ & $4^{\text {th }} \mathrm{hr}$ \\
\hline Distilled Water & $2 \mathrm{ml}$ & $0.3 \pm 0.04$ & $0.6 \pm 0.05$ & $0.7 \pm 0.06$ & $0.8 \pm 0.11$ & - & - & - & - \\
\hline Diclofenac Sodium & $40 \mathrm{mg}$ & ${ }^{*} 0.2 \pm 0.04$ & ${ }^{*} 0.3 \pm 0.07$ & ${ }^{* *} 0.3 \pm 0.03$ & ${ }^{* *} 0.3 \pm 0.04$ & $39 \%$ & $46 \%$ & $59 \%$ & $61 \%$ \\
\hline D. pauciflorum & $2 \mathrm{gm}$ & NS0. $2 \pm 0.04$ & ${ }^{*} 0.3 \pm 0.06$ & ${ }^{*} 0.4 \pm 0.06$ & NS0. $6 \pm 0.0$ & $38 \%$ & $40 \%$ & $32 \%$ & $33 \%$ \\
\hline M. indica & $2 \mathrm{gm}$ & NS0.2 \pm 0.04 & ${ }^{*} 0.3 \pm 0.06$ & ${ }^{*} 0.4 \pm 0.06$ & NS0.6 \pm 0.0 & $21 \%$ & $35 \%$ & $37 \%$ & $29 \%$ \\
\hline A. paniculata & $2 \mathrm{gm}$ & NS0. $2 \pm 0.04$ & ${ }^{*} 0.3 \pm 0.05$ & ${ }^{*} 0.4 \pm 0.06$ & NS0. $5 \pm 0.07$ & $21 \%$ & $38 \%$ & $39 \%$ & $34 \%$ \\
\hline
\end{tabular}

NS $=$ not significant, $*$ significant $(P<0.05)$ and $* *$ highly significant $(P<0.01)$ compared to control

performed by one way analysis of variance (ANOVA) and unpaired student's t test.

\section{Results}

Analgesic activity: Table- 1 shows the pain behavior of writhing response of mice and analgesic activities of Diclofenac sodium and ethanol extract of plant leaves. The control animal showed 66.7 writhing count $/ 20$ minutes but, animal treated with Diclofenac sodium caused significant reduction of writhing count, from 66.7 to $16.5(p<0.01)$. Animals treated with leaves extract of Desmodium pauciflorum, Mangifera indica and Andrographis paniculata reduced the writhing count from 66.7 to $43.5,29.5$ and 44.2 , respectively. The results suggested ethanol extract leaves and Diclofenac sodium had analgesic action and showed significant $(p<0.01)$ reduction of pain in comparison with control group. Mangifera indica had higher analgesic activity (56\%) than other leaves extract (34$35 \%)$.

Anti-inflammatory activity: Table- 2 showed that the paw edema were significantly $(p<0.05$ and $p<0.01)$ lees in $2^{\text {nd }}$ and $3^{\text {rd }}$ hours in both ethanol extracted leaves and diclofenac sodium in comparison with control group. On the other hand $1^{\text {st }}$ and $4^{\text {th }}$ hours there were no significant variation of paw edema among the treated and control animals. Among the extract of leaves of Desmodium pauciflorum, Mangifera indica and Andrographis paniculata the anti-inflammatory effects at $1^{\text {st }} \mathrm{hr}, 2^{\text {nd }} \mathrm{hr}, 3^{\text {rd }} \mathrm{hr}$ and $4^{\text {th }} \mathrm{hr}$ were $38 \%, 40 \%$, $32 \%, 33 \%$ and $21 \%, 35 \%, 37 \%, 29 \%$ and $21 \%, 38 \%$, $39 \%, 34 \%$ respectively. The overall anti-inflammatory activity was highest in leaves extract of Desmodium pauciflorum followed by Andrographis paniculata and Mangifera indica.

\section{Discussion}

Analgesic activity: The writhing test has long been used as a screening tool for the evaluation of analgesic properties of new substances. Ethanol extracted leaves of Desmodium pauciflorum, Mangifera indica and Andrographis paniculata showed significant inhibition $(p<0.01)$ of acetic acid induced writhing response of mice, so it can be suggested that those leaves extract has potential analgesic activities. The analgesic effect of the extract may be either due to its action on visceral receptor sensitive to acetic acid, to the inhibition of the algogenic substances or the inhibition of transmission of painful messages at the central level $[14,15]$. The special nerve endings that sense pain are very sensitive to prostaglandin. When prostaglandin is released, the nerve endings respond to it through prostaglandin $\mathrm{E}_{2}$ $\left(\mathrm{PGE}_{2}\right)$ receptor by picking up and transmitting the pain and injury messages through the nervous system to the brain and cause visceral writhing stimuli in mice [16]. Therefore, it has been suggested that the inhibition of prostaglandin synthesis is remarkably efficient as an anti-nociceptive mechanism in visceral pain [17]. Acetic acid induced abdominal constriction is a useful experimental tool in testing of new analgesic drugs [18]. The abdominal injection of acetic acid in mice has been attributed to the release of arachidonic acid, which results synthesis of prostaglandin via the cyclooxygenase (COX) enzyme [19]. The results support the popular use of mentioned plant leaves extract, but phytochemical studies together with pharmacological and toxicological investigations have proven essential for the complete understanding of their medicinal application.

Anti-inflammatory activity: In the present study, the anti-inflammatory effects of the ethanol extract of leaves were demonstrated in an in vitro animal model, which focused on the inhibitory effect of the extract on anti-inflammatory activity. Inflammation can be defined as the response of living tissues to injury which involves a complex array of enzyme activation, mediator release, and extravasations of fluid, cell migration, tissue breakdown and repair [20]. The antiinflammatory effects may be elicited by a variety of chemicals agents and that there is no remarkable correlation between their pharmacological activity and chemical structure [21]. We evaluate the antiinflammatory activity of ethanol extracted leaves of Desmodium pauciflorum, Mangifera indica and Andrographis paniculata by Carrageenan induced paw edema model which is an established model for evaluating anti-inflammatory activity. Development of edema in the paw of rats after injection of carrageenen is a biphasic event [22]. The initial phase observed during the first hour is attributed to the release of histamine and serotonin. The second phase of edema is due to the release of prostaglandins, protease, and lysosome [23-25]. A significant anti-inflammatory effect was showed in leaves extract of Abies pindrow Royle, and the highest dose being comparable to phenylbutazone [26] in the carrageenin induced paw edema in rats. Our findings not only provided experimental evidence for an anti-inflammatory mechanism but were also beneficial to future research 
about the effect of mentioned leaves extract on other diseases. Identification of active compounds with remedial applications is a challenge and needs to be investigated further.

\section{Conclusion}

The effects of ethanol extracted leaves of plants showed significant reduction of pain in comparison with available commercial analgesic drugs. They had also anti-inflammatory effect. However, further investigation is required for isolation, identification and characterization of different active compounds and their mode of action and therapeutic range.

\section{Authors' contribution}

MMH, SAK and SI implemented the study design and carried out the laboratory experimentation. MMH, AHS, MEH, MAH and MHU drafted and revised the manuscript. All authors read and approved the final version of manuscript.

\section{Acknowledgements}

Authors are grateful to the University Grants Commission (UGC) of Bangladesh for giving financial support to the present research project and also thankful to the management and administrative authorities of BCSIR, Chittagong for their laboratory support and encouragement.

\section{Competing interests}

Authors declare that they have no competing interests.

\section{References}

1. Edeogra H.O. (2005). Phytochemical constituents of some Nigerian Medicinal plants, Afr J Biotechnol., 4(7): 685-688.

2. Hassan M.M., Saha A.K., Khan S.A., Islam A., MahabubUz-Zaman M., Ahmed S.S.U. (2011). Studies on the antidiarrhoeal, antimicrobial and cytotoxic activities of ethanol-extracted leaves of yellow oleander (Thevetia peruviana), Open Vet.J., 1:28-31.

3. Hassan M.M., Shahinuzzaman A.B.M., Khan S.A., Uddin M. B., Mahabub-Uz-Zaman M. (2011). AntiDiarrhoeal, Antimicrobial and Cytotoxic Effect of Ethanol Extracted Guava (Psidium guajava) Leaves, Vet Scan, 6(2):91.

4. Oliveira A.M., Conserva L.M., de Souza Ferro J.N., Brito F.A., Lemos R.P.L., Barreto E. (2012). Antinociceptive and Anti-Inflammatory Effects of Octacosanol from the Leaves of Sabicea grisea var. grisea in Mice. Int. J. Mol. Sci., 13, 1598-1611.

5. Coe F.G., Anderson G.J. (1996). Screening of medicinal plants used by the Gar'ifuna of eastern Nicaragua for bioactive compounds, J. Ethnopharmacol, 53:29-50.

6. de Sousa O.V., Vieira G.D., De Pinho J.J.R.G., Yamamoto C.H., Alves M.S. (2010). Antinociceptive and antiinflammatory activities of the ethanol extract of Annona muricata L. leaves in animal models. Int. J. Mol. Sci, 11, 2067-2078.

7. Mishra P., Pal N. L., Guru P. Y., Katiyar J. C., Srivastava V., Tandon J. S. (1992). Anti-malarial activity of Andrographis paniculata (Kalmegh) against Plasmodium berghei NK65 in Mastomys natalensis, Int J Pharmacog., 30: 263-274.

8. Karou S.D., Tchacondo T., Ilboudo D.P., Simpore J. (2011). Sub-Saharan Rubiaceae: A review of their traditional uses, phytochemistry and biological activities. Pak. J. Biol.Sci, 14, 149-169.
9. Madav S., Tripathi H., Tandan C., Mishra S. K. (1995). Analgesic, antipyretic and anti-ulcerogenic effects of andrographolide, Ind J Pharm Sci., 57: 121-125.

10. Thomas M.C. (2000). Diuretics, ACE inhibitors and NSAIDs - the triple whammy, MedJAust, 172:184-185.

11. Ahmad F., Khan R.A., Rasheed S. (1992). Study of analgesic and anti-inflammatory activity from plant extracts of Lactuca scariola and Artemisia absinthium, Journal Islam Aca Sci., 5: 111-114.

12. Koster R., Anderson M., de Beer E.J. (1959). Acetic acid for analgesic screening. Fed Proc., 18: 412.

13. Winter, C.A., Risley, E.A. and Nuss G.W. (1962). Carrageenin-induced edema in hind paw of the rat as an assay for anti-inflammatory drugs, Proc Soc Exp Biol Med., 111: 544-547.

14. Hosseinzadeh, H. and Younesi H. M. (2002) Antinociceptive and anti- inflammatory effects of Crocus sativus L. stigma and petal extracts in mice, BMC Pharmacology 2:7.

15. Hosoi M. (1999). Prostaglandin E (2) has antinociceptive effects through EP (1) receptor in the ventromedial hypothalamus in rats, Pain, 83:221-227.

16. da Silva J.B., Temponi V.S., Fernandes F.V., Alves G.A.D., Matos D.M., Gasparetto C.M., Ribeiro A., de Pinho J.J.R.G., Alves M.S., de Sousa O.V. (2011). New Approaches to Clarify Antinociceptive and Anti-Inflammatory Effects of the Ethanol Extract from Vernonia condensata Leaves. Int. J. Mol. Sci., 12, 8993-9008.

17. Franzotti E.M., Santos C.V., Rodrigues H.M., Mourao R.H., Andrade M.R., Antoniolli A.R. (2002). Anti-inflammatory, analgesic and acute toxicity of Sida cadifolia L., $J$ Ethnopharmacol., 72: 273-278.

18. Otterness I., Bliven M. (1985). Laboratory models for testing nonsteroidal antiinflammatory drugs, J. Lombardino, editor. John Wiley \& Sons Inc. New York, New York, USA. $112-251$.

19. Farias J.A., Ferro J.N., Silva J.P., Agra I.K., Oliveira F.M., Candea A.L., Conte F.P., Ferraris F.K., Henriques M.D., Conserva L.M. (2011). Modulation of inflammatory processes by leaves extract from Clusia nemorosa both in vitro and in vivo animal models. Inflammation, doi:10.1007/s10753-0119372-y.

20. Risso W.E., Scarminio I.S., Moreira E.G. (2010). Antinociceptive and acute toxicity evaluation of Vernonia condensata Baker leaves extracted with different solvents and their mixtures. Indian J. Exp. Biol, 48, 811-816.

21. Nagar A, Shukla AK, Bigoniya P. (2011). Anti-inflammatory potential of Spinacia oleracea leaf extract. J Nat Pharm, 2:80-7.

22. Sousa O.V., Del-Vechio-Vieira G., Pinho J.J.R.G., Yamamoto C.H., Alves M.S. (2010) Antinociceptive and anti-inflammatory activities of the ethanol extract of Annona muricata L. leaves in animal models. Int. J. Mol. Sci, 11, 2067-2078.

23. Asongalem E. A., Foyet H. S., Ekoo S., Dimo T., Kamtchouing P. (2004). Anti-inflammatory, lack of central analgesia and antipyretic properties of Acanthusmontanus (Ness), J Ethnopharmacol., 95: 63-68.

24. Silva G. N., Martins F. R., Matheus, M. E. (2005). nvestigation of anti-inflammatory and antinociceptive activities of Lantana trifolia, J Ethnopharmacol., 100 :254259.

25. Panthong A., Kanjanapothi D., Taesotikul T., Phankummoon A., Panthong K., Reutrakul V. (2004). Anti-inflammatory activity of methanolic extracts from Ventilago harmandiana Pierre, JEthnopharmacol., 91: 237-42.

26. Singh N., Mishra P.K., Kapil A., Arya K.R., Maurya R., Dube A. (2001). Efficacy of Desmodium gangeticum extract and its fractions against experimental visceral leishmanisis, $J$ Ethnopharmacol., 98:83-88.

\section{$* * * * * * * *$}

